\title{
Review \\ The Role of Neuropeptide B and Its Receptors in Controlling Appetite, Metabolism, and Energy Homeostasis
}

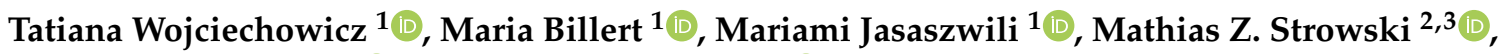 \\ Krzysztof W. Nowak ${ }^{1}$ (D) and Marek Skrzypski ${ }^{1, *(D)}$ \\ 1 Department of Animal Physiology, Biochemistry and Biostructure, Poznań University of Life Sciences, \\ 35 Wołyńska St, 60-637 Poznań, Poland; tatiana.wojciechowicz@up.poznan.pl (T.W.); \\ maria.billert@up.poznan.pl (M.B.); mariami.jasaszwili@up.poznan.pl (M.J.); \\ kwnowak@up.poznan.pl (K.W.N.) \\ 2 Department of Hepatology and Gastroenterology, Charité-University Medicine Berlin, D-13353 Berlin, \\ Germany; mathias.strowski@charite.de \\ 3 Department of Internal Medicine-Gastroenterology, Park-Klinik Weissensee, D-13086 Berlin, Germany \\ * Correspondence: marek.skrzypski@up.poznan.pl
}

\section{check for} updates

Citation: Wojciechowicz, T.; Billert, M.; Jasaszwili, M.; Strowski, M.Z.; Nowak, K.W.; Skrzypski, M. The Role of Neuropeptide B and Its Receptors in Controlling Appetite, Metabolism, and Energy Homeostasis. Int. J. Mol. Sci. 2021, 22, 6632. https://doi.org/ $10.3390 /$ ijms 22126632

\section{Academic Editors:}

Katalin Prokai-Tatrai, Jaroslav Kuneš, Lenka Maletinska and Blanka Železná

Received: 29 April 2021

Accepted: 18 June 2021

Published: 21 June 2021

Publisher's Note: MDPI stays neutral with regard to jurisdictional claims in published maps and institutional affiliations.

Copyright: (c) 2021 by the authors. Licensee MDPI, Basel, Switzerland. This article is an open access article distributed under the terms and conditions of the Creative Commons Attribution (CC BY) license (https:// creativecommons.org/licenses/by/ $4.0 /)$.

\begin{abstract}
Neuropeptide B (NPB) is a peptide hormone that was initially described in 2002. In humans, the biological effects of NPB depend on the activation of two G protein-coupled receptors, NPBWR1 (GPR7) and NPBWR2 (GPR8), and, in rodents, NPBWR1. NPB and its receptors are expressed in the central nervous system (CNS) and in peripheral tissues. NPB is also present in the circulation. In the CNS, NPB modulates appetite, reproduction, pain, anxiety, and emotions. In the peripheral tissues, NPB controls secretion of adrenal hormones, pancreatic beta cells, and various functions of adipose tissue. Experimental downregulation of either NPB or NPBWR1 leads to adiposity. Here, we review the literature with regard to NPB-dependent control of metabolism and energy homeostasis.
\end{abstract}

Keywords: appetite; neuropeptide B; NPBWR1; NPRBWR2; metabolism; energy homeostasis

\section{Introduction}

Peptides that regulate appetite play a prominent role in controlling energy homeostasis and whole-body metabolism. Such peptides are found in brain regions that are involved in the modulation of appetite. In addition, such peptides are present in the circulation and in numerous peripheral tissues. There is growing evidence indicating that peptides that control appetite (e.g., kisspeptin, orexins, spexin, adropin, apelin, phoenixin, ghrelin, amylin, and pancreatic peptides) also modulate the endocrine activity of endocrine glands as well as lipid and glucose metabolism [1-6]. Moreover, some peptides are involved in regulating the endocannabinoid system and, through it, food intake, e.g., hemopressin, a small peptide derived from the $\alpha$-chain of hemoglobin, reduces appetite through increased levels of endocannabinoids $[7,8]$. On the other hand, endogenous cannabinoids can also increase the secretion of feeding-regulated hypothalamic neuropeptides [9]. Thus, peptide hormones and their receptors may be of interest in therapy for obesity and obesity-related diseases such as type 2 diabetes [1]. Almost 20 years after the discovery of neuropeptide B (NPB), there is growing evidence that this peptide modulates food intake, body weight, and lipid and glucose metabolism. In our narrative review, we discuss current findings regarding the role of NPB and its receptors in controlling food intake and energy homeostasis.

\section{Discovery, Structure, and Expression of NPB and Its Receptors}

By analyzing human genomic sequences in the Celera database, in 2002, Fuji et al. identified a new neuropeptide composed of 23 or 29 amino acids that was uniquely modified with bromine. This peptide was termed neuropeptide B (NPB) [10]. The same study showed that NPB interacts with NPBWR1 (GPR7) and less potently with NPBWR2 
(GPR8) [10]. At the same time, NPB as a ligand of NPBWR1 and NPBWR2 was reported by two independent laboratories [11,12]. Both NPBWR1 and NPBWR2 belong to the G proteincoupled receptor superfamily [13]. It is important to note that humans express both types of receptors, while rodents express only NPBWR1 [14]. It should be pointed out that both types of NPB receptors interact with another ligand, termed neuropeptide W [11,15]. The intracellular signaling of NPBWR1 and NPBWR1 encompasses the modulation of cAMP, calcium, phospholipase $\mathrm{C}$, or MAP kinase signaling $[10,11,16,17]$. The expression of NPB and its receptors in the CNS and various peripheral tissues was reported (Tables 1 and 2).

Table 1. Localization of NPB in central nervous system and peripheral tissues.

\begin{tabular}{|c|c|c|c|c|c|c|}
\hline & RT-PCR & ISH & IHC ICC IF & WB & NB & References \\
\hline Whole brain & $\mathrm{F}$ & - & - & $\mathrm{F}$ & - & {$[18,19]$} \\
\hline Telencephalic area $(\mathrm{Vs} / \mathrm{Vp})$ & - & $\mathrm{F}$ & $\mathrm{F}$ & - & $\mathrm{F}$ & {$[18,19]$} \\
\hline $\begin{array}{l}\text { Magnocellular/gigantocellular portions of } \\
\text { magnocellular preoptic nucleus (PMm/PMg) }\end{array}$ & - & $\mathrm{F}$ & $\mathrm{F}$ & - & $\mathrm{F}$ & [18-20] \\
\hline Telencephalon & $\mathrm{Ch}$ & - & - & - & - & {$[21]$} \\
\hline Cerebral cortex & Rt & - & - & - & - & [10] \\
\hline Striatum & Rt & - & - & - & - & [10] \\
\hline Hippocampus & Rt, $\mathrm{P}$ & M, Rt & - & - & - & {$[10,11,22,23]$} \\
\hline Thalamus & Rt & - & - & - & - & [10] \\
\hline Hypothalamus & Rt, $\mathrm{Ch}$ & - & Rt & - & - & {$[10,21,24]$} \\
\hline Midbrain & $\mathrm{Rt}, \mathrm{Ch}$ & - & - & - & - & {$[10,21]$} \\
\hline Cerebellum & Rt, $\mathrm{P}, \mathrm{Ch}$ & - & Rt & - & - & {$[10,21,23,24]$} \\
\hline Medulla oblongata & Rt & - & - & - & - & [10] \\
\hline Spinal cord & $\mathrm{Rt}, \mathrm{P}, \mathrm{Ch}$ & - & $\mathrm{F}$ & - & - & {$[10,19,21,23]$} \\
\hline Lateral habenular nucleus (LHb) & - & M & - & - & - & [11] \\
\hline Paraventricular hypothalamic nucleus (PVN) & - & $\mathrm{M}$ & Rt & - & - & {$[11,24]$} \\
\hline Edinger-Westphal nucleus & - & M, Rt & - & - & - & {$[22,24]$} \\
\hline Motor root of trigeminal nerve (m5) & - & $\mathrm{M}$ & - & - & - & [11] \\
\hline Sensory root of trigeminal nerve (s5) & - & M & - & - & - & {$[11]$} \\
\hline Lateral parabrachinal nucleus internal part (LPBI) & - & M & - & - & - & [11] \\
\hline Mesencephalic trigeminal nucleus (Me5) & - & M & - & - & - & [11] \\
\hline Subcoeruleus nucleus alpha part (Sub CA) & - & M & - & - & - & {$[11]$} \\
\hline Locus coeruleus (LC) & - & M, Rt & - & - & - & {$[11,22]$} \\
\hline Noradrenergic cell group A5 & - & $\mathrm{M}$ & - & - & - & [11] \\
\hline Interior olive subnucleus B (OIB) & - & M & - & - & - & [11] \\
\hline Anterior olfactory nucleus & - & Rt & - & - & - & [22] \\
\hline Piriform cortex & - & Rt & & - & - & [22] \\
\hline Supraoptic nucleus (SON) & - & - & Rt & - & - & [24] \\
\hline Median preoptic nucleus & - & Rt & - & - & - & [22] \\
\hline Basolateral amygdala & - & Rt & - & - & - & [22] \\
\hline Medial tuberal nucleus & - & Rt & - & - & - & [22] \\
\hline Substantia nigra & - & Rt & - & - & - & {$[22]$} \\
\hline Dorsal raphne nucleus & - & Rt & - & - & - & [22] \\
\hline Pituitary gland & $\mathrm{Rt}, \mathrm{Ch}$ & - & Rt & - & - & {$[10,21,24]$} \\
\hline Eyeball and optic nerve & Rt, F (eye) & - & - & - & - & {$[10,18]$} \\
\hline Gill & $\mathrm{F}$ & - & - & - & - & [18] \\
\hline Thyroid gland & Rt & - & Rt & - & - & {$[10,24]$} \\
\hline Trachea & Rt & - & - & - & - & [10] \\
\hline Thymus & Rt, P & - & - & - & - & {$[10,23]$} \\
\hline Tonsil & $\mathrm{P}$ & - & - & - & - & [23] \\
\hline Heart & Rt. $\mathrm{Ch}$ & - & $\mathrm{Rt}$ & Rt & - & {$[10,21,25]$} \\
\hline Lung & Rt, Ch & - & - & - & - & {$[10,21]$} \\
\hline Liver & $\mathrm{Rt}, \mathrm{Ch}, \mathrm{F}$ & - & - & - & - & {$[10,18,21]$} \\
\hline Spleen & Rt, Ch & - & - & - & - & {$[10,21]$} \\
\hline Lymph node & Rt & - & - & - & - & [10] \\
\hline Pancreas & $\mathrm{Rt}, \mathrm{Ch}$ & - & Rt & - & - & {$[10,21,24]$} \\
\hline Kidney & Rt, $\mathrm{Ch}$ & - & - & - & - & {$[10,21]$} \\
\hline
\end{tabular}


Table 1. Cont.

\begin{tabular}{|c|c|c|c|c|c|c|}
\hline & RT-PCR & ISH & IHC ICC IF & WB & NB & References \\
\hline $\begin{array}{l}\text { Adrenal gland (adrenal medulla, adrenal cortex: } \\
\text { zonae glomerulosa and fasciculata/reticularis) }\end{array}$ & Rt & - & Rt & - & - & {$[10,24,26]$} \\
\hline Urinary bladder & Rt & - & - & - & - & [10] \\
\hline Peritoneum & Rt & - & - & - & - & [10] \\
\hline Stomach & - & - & - & - & - & [10] \\
\hline Duodenum, jejunum, ileum, cecum, colon, rectum & Rt, $\mathrm{P}, \mathrm{Ch}$ & - & - & - & - & {$[10,21,23]$} \\
\hline Intestine & $\mathrm{F}$ & - & - & - & - & [18] \\
\hline Skeletal muscle & $\mathrm{Rt}, \mathrm{Ch}$ & - & - & - & - & {$[10,21]$} \\
\hline Prostate & Rt & - & - & - & - & [10] \\
\hline Seminal vesicle & Rt & - & - & - & - & [10] \\
\hline Testes & Rt, P, Ch, F & - & Rt & - & - & {$[10,18,21,23,24]$} \\
\hline Ovary & Rt, $\mathrm{P}, \mathrm{Ch}, \mathrm{F}$ & - & Rt & - & - & {$[10,18,21,23,24]$} \\
\hline Uterus & Rt & - & - & - & - & [10] \\
\hline Placenta & Rt & - & - & - & - & [10] \\
\hline Mammary gland & Rt & - & - & - & - & [10] \\
\hline Skin & $\mathrm{Rt}, \mathrm{Ch}$ & - & - & - & - & {$[10,21]$} \\
\hline Femur & Rt & - & - & - & - & [10] \\
\hline Bone marrow & Rt & - & - & - & - & [10] \\
\hline Costal cartilage & Rt & - & - & - & - & [10] \\
\hline White adipose tissue & $\mathrm{Rt}, \mathrm{Ch}$ & - & - & - & - & {$[10,21,27]$} \\
\hline Brown adipose tissue & Rt & - & - & - & - & {$[10,28]$} \\
\hline Fetus & Rt & - & - & - & - & [10] \\
\hline Embryo & $\mathrm{F}$ & $\mathrm{F}$ & - & - & - & [18] \\
\hline
\end{tabular}

RT-PCR, real-time PCR; ISH, in situ hybridization; ICH, immunohistochemistry; ICC, immunocytochemistry; IF, immunofluorescence; Rt, rat; $\mathrm{M}$, mouse; $\mathrm{H}$, human; $\mathrm{P}$, pig; $\mathrm{Ch}$, chicken; $\mathrm{F}$, medaka fish

Table 2. Localization of NPBWR1 (R1) and NPBWR2 (R2) in central nervous system and peripheral tissues.

\begin{tabular}{|c|c|c|c|c|c|}
\hline & RT-PCR & ISH & IHC ICC IF & WB & Reference \\
\hline Telencephalon & Ch (R1, R2) & $\mathrm{F}(\mathrm{R} 2)$ & - & - & {$[19,21]$} \\
\hline Cerebral cortex & Rt (R1) & - & - & - & {$[10]$} \\
\hline Striatum & Rt (R1) & - & - & - & [10] \\
\hline Hippocampus & Rt (R1) & M & - & - & {$[10]$} \\
\hline Thalamus & Rt (R1) & $\mathrm{F}(\mathrm{R} 2)$ & - & - & {$[10,19]$} \\
\hline Hypothalamus & Rt (R1), Ch (R1, R2) & Rt (R1), F (R2) & - & - & {$[10,19,21,22,24]$} \\
\hline Midbrain & Rt (R1), Ch (R1, R2) & $\mathrm{F}(\mathrm{R} 2)$ & - & - & {$[10,19,21]$} \\
\hline Cerebellum & $\mathrm{Rt}(\mathrm{R} 1)$ & - & - & - & [10] \\
\hline Medulla oblongata & Rt (R1) & - & - & - & [10] \\
\hline Amygdala & - & Rt (R1) & - & - & [22] \\
\hline Suprachiasmatic nucleus & - & Rt (R1) & - & - & [22] \\
\hline Ventral tuberomammillary nucleus & - & Rt (R1) & - & - & {$[22]$} \\
\hline Dorsal endopiriform & - & Rt (R1) & - & - & [22] \\
\hline Dorsal tenia tecta & - & Rt (R1) & - & - & [22] \\
\hline Bed nucleus & - & Rt (R1) & - & - & [22] \\
\hline Red nucleus & - & Rt (R1) & - & - & [22] \\
\hline Parastrial nucleus & - & Rt (R1) & - & - & [22] \\
\hline Laterodorsal tegmentum & - & Rt (R1) & - & - & [22] \\
\hline Superior colliculus & - & Rt (R1) & - & - & {$[22]$} \\
\hline Locus coeruleus & - & Rt (R1) & - & - & [22] \\
\hline Nucleus of solitary tract & - & Rt (R1) & - & - & [22] \\
\hline Spinal cord & Rt (R1), Ch (R1, R2) & $\mathrm{F}(\mathrm{R} 2)$ & - & - & {$[10,19,21]$} \\
\hline Pituitary gland & Rt (R1), Ch (R2) & $F(R 2)$ & - & Ch (R1, R2) & {$[10,19,21,24]$} \\
\hline Eyeball and optic nerve & Rt (R1) & - & - & - & [10] \\
\hline Thyroid gland & Rt (R1) & - & - & - & {$[10,24]$} \\
\hline Trachea & Rt (R1) & - & - & - & {$[10]$} \\
\hline
\end{tabular}


Table 2. Cont.

\begin{tabular}{|c|c|c|c|c|c|}
\hline & RT-PCR & ISH & IHC ICC IF & WB & Reference \\
\hline Thymus & Rt (R1) & - & - & - & [10] \\
\hline Lung & Rt (R1) & - & - & - & [10] \\
\hline Heart & Rt (R1) & - & Rt (R1) & Rt (R1) & {$[25]$} \\
\hline $\begin{array}{l}\text { Adrenal gland (adrenal medulla, } \\
\text { adrenal cortex: zonae glomerulosa } \\
\text { and fasciculata/reticularis) }\end{array}$ & Rt (R1) & - & - & - & {$[10,24,26]$} \\
\hline Stomach & Rt (R1) & - & - & - & [10] \\
\hline $\begin{array}{l}\text { Duodenum, jejunum, ileum, cecum, } \\
\text { colon, rectum }\end{array}$ & Rt (R1), Ch (R1) & - & - & - & {$[10,21]$} \\
\hline Testes & Rt (R1), P (R1, R2) & - & - & - & {$[10,23,24]$} \\
\hline Ovary & Rt (R1), P (R1, R2) & - & - & - & {$[10,23,24]$} \\
\hline Uterus & Rt (R1) & - & - & - & [10] \\
\hline Placenta & Rt (R1) & - & - & - & [10] \\
\hline Mammary gland & Rt (R1) & - & - & - & [10] \\
\hline Skin & Rt (R1) & - & - & - & {$[10]$} \\
\hline Fetus & Rt (R1) & - & - & - & [10] \\
\hline Pancreas & $\mathrm{Ch}(\mathrm{R} 2)$ & - & - & - & [21] \\
\hline Spleen & $\mathrm{Ch}(\mathrm{R} 2)$ & - & - & - & {$[21]$} \\
\hline Muscle & Ch (R1) & - & - & - & [21] \\
\hline Brown preadipocytes & Rt (R1) & - & - & - & {$[28]$} \\
\hline White adipocytes & Rt (R1) & - & - & - & [27] \\
\hline
\end{tabular}

RT-PCR, real-time PCR; ISH, in situ hybridization; ICH, immunohistochemistry; ICC, immunocytochemistry; IF, immunofluorescence; Rt, rat; $\mathrm{M}$, mouse; $\mathrm{H}$, human; $\mathrm{P}$, pig; $\mathrm{Ch}$, chicken; $\mathrm{F}$, medaka fish.

\section{The Role of NPB in Appetite Modulation}

The initial study showed that NPB mRNA is expressed in brain regions that are crucially relevant in the regulation of food intake. NPB mRNA was reported in the dorsomedial, paraventricular, and arcuate nuclei [11]. In their pioneer work, Tanaka et al. investigated the effects of NPB administration on food intake in mice. Initially, the authors investigated the effects of NPB administration on appetite during the light phase. However, they did not observe any influence of NPB on appetite control in animals. In contrast, i.c.v. administration of NPB during the dark phase led to stimulated food intake during the first $2 \mathrm{~h}$ [11]. In contrast, after 2 more hours, NPB caused appetite suppression. The same study evaluated the effects on appetite of co-administration of NPB and corticotropin-releasing factor (CRF), a well-known suppressor of food intake [29]. Tanaka et al. reported that CRF significantly enhanced the suppression of appetite induced by NPB, suggesting an interaction between CRF and urocortin systems [11]. In summary, this study showed, for the first time, that the effects of NPB on food intake are biphasic.

The anorexigenic activity of the NPB/NPBW1 system was additionally confirmed by Ishii et al., who found that GPR7- / - male mice ate more food than wild-type GPR7 mice [30]. It is worth noting that GPR7- / - mice had reduced NPY mRNA and increased POMC mRNA expression in the hypothalamus. Of note, NPY promotes food intake, while POMC has the opposite effect [31]. Another animal study showed that i.c.v. administration of NPB (during the light phase) in male rats promoted feeding behavior [32]. Stimulation of food intake was detected $30 \mathrm{~min}$ after NPB administration and lasted at least $4 \mathrm{~h}$. In contrast, NPB did not affect water intake [32]. It is important to note that, in contrast to NPBW1-/ - mice, NPB - / - mice had a normal feeding behavior [33]. Studies addressing the role of NPB in appetite regulation are not restricted to rodents. For instance, it was found that i.p. injection of NPB stimulated mRNA expression of NPY and CCK1 in the hypothalamus of Nile tilapia Oreochromis niloticus [34]. Since NPY stimulates food intake and CCK1 suppresses appetite [35], it is difficult to define the role of NPB in controlling feeding behavior in tilapia, and more studies need to be conducted.

Discussing the contribution of NPB to appetite modulation, it is worth noting that a human study was conducted on circulating NPB in blood in patients with anorexia 
nervosa (AN). Grzelak et al. reported that patients who suffer from AN are characterized by lower levels of NPB in the circulation compared to healthy controls, suggesting the use of NPB in diagnosing AN [36]. Nevertheless, as pointed out in this work, NPB levels were evaluated in only 30 healthy controls and 46 patients with anorexia [36]; therefore, these results should be interpreted cautiously. The downregulation of circulating NPB levels in patients with anorexia was independently confirmed by a study of 30 healthy controls and 30 patients with AN [37]. Importantly, this study additionally showed that increased NPB levels are not affected by body weight normalization after hospitalization [37]. More studies are needed to elucidate the potential role of NPB in the diagnosis of AN.

In summary, animal studies have shown that i.c.v. administration of NPB during the dark phase biphasically modulates food intake. NPB promotes food intake during the first $2 \mathrm{~h}$, followed by appetite suppression. In contrast, rat studies showed that NPB displays orexigenic effects during the light phase. The role of NPB in controlling feeding behavior is complex; therefore, more studies are needed.

\section{The Role of NPB in Brain}

Beside its role in feeding behavior, in the CNS, NPB modulates locomotion and analgesia [11]. An i.c.v. injection of NPB in rats significantly increased locomotion in an open-field test in both the bright and dark phases. On the other hand, Hirashima et al. demonstrated that i.c.v. injection of NPB in mice reduced locomotor activity during the dark period, but not during the light phase. The activity of mice was measured using an infrared activity monitor [38]. In experiments using $\mathrm{Npb}-/-$ mice, no significant differences in activity levels were found compared to littermate controls [33].

In the CNS, NPB impacts analgesia. Tanaka et al. reported that i.c.v. injection of NPB in rats reduced licking duration in the formalin test, which indicates an analgesic role of the peptide against chemically induced pain [11]. These effects could be conferred via NPB and NPBWR1, which are found in the periaqueductal gray matter and amygdala, areas that are also known to express opioid receptors [39]. It is worth mentioning that NPBWR1 binds non-selective opioid ligands such as $\beta$-endorphin [13]. The analgesic effect of NPB was also observed after intrathecal injection in the formalin test, and mechanical allodynia was inducible by carrageenan injection [40]. However, NPB had no effect on the level of thermal hyperalgesia induced by paw carrageenan injection in rats [40] and NPB-/ mice [33].

The pain response is tightly connected to anxiety [41]. The role of NPB in regulating anxiety has been investigated using the cued and contextual fear test and elevated plus maze test. NPBWR1-/ - mice had similar behavior in the contextual fear test compared to wild-type mice [42]. However, unlike wild-type mice, NPBWR1-/- mice showed behavioral changes in social interactions [42]. The role of NPB in the context of social behavior was evaluated by Watanabe et al. [43]. They showed that genetic changes in NPWR1 (single-nucleotide polymorphism at nucleotide 404 resulted in an amino acid change, Y135F) modulated emotional responses to facial expression. The 404AT subjects were less submissive to angry faces than 404AA subjects.

There is evidence that NPB is involved in sleep/wakefulness [38]. An i.c.v. injection of NPB in mice during the dark period decreased time in the waking state and increased time in slow-wave sleep, whereas no change in paradoxical sleep time was observed. Moreover, NPBWR1+/ - and NPBWR1 - / - mice did not present any abnormalities compared with wild-type mice, indicating a modulatory role of NPB and NPBWR1 in the sleep/wakefulness pattern [38].

In summary, NPB plays a role in the regulation of locomotion and decreases locomotor activity during the dark phase. Moreover, during the dark period, NPB decreases the waking state time. It also plays an analgesic role in chemically induced pain and decreases social anxiety. 


\section{The Role of NPB in Regulating Glucose and Lipid Metabolism \\ 5.1. In Vivo Lessons from Genetically Engineered Animals}

An animal study performed with NPBWR1-/ - mice showed that NPB/NPBWR may play a role in controlling energy hemostasis and body weight regulation. It was reported that depletion of NPBWR1 was accompanied by increased body weight in animals fed a standard or high-fat diet [30]. Notably, this effect was observed only in male animals [30]. An analysis of body composition in male NPBWR1 $1-/-$ mice showed that total body fat mass was two times higher compared to NPBWR1+/+ animals [30]. Furthermore, male NPBWR1-deficient mice had decreased spontaneous locomotor activity, reduced oxygen consumption, and lower energy expenditure. Additionally, it was found that NPBWR1-/males at 52 weeks of age had increased blood glucose, leptin, and insulin levels. Sexdependent effects of NPBWR1 depletion on body weight and metabolic parameters are not completely understood. However, it is unlikely that sex hormones have a role in this context. The contribution of the NPB/NPBWR1 system to body weight control was additionally studied by Kelly et al. using NPB-depleted mice. This study showed that male $\mathrm{NPB}-/-$ and $\mathrm{NPB}+/-$ mice gained more body weight in response to feeding with low-fat chow (6\%) compared with wild-type animals [33]. Overall, these in vivo studies show that the downregulation/depletion of NPBWR1 or NPB leads to an increased body weight, accompanied by decreased energy expenditure.

\subsection{The Role of NPB in Controlling Members of the Adipoinsular Axis}

The contribution of the NPBWR1/NPB system to energy homeostasis is additionally supported by in vitro studies suggesting that NPB may interact with fat tissue and pancreatic beta cells. There is growing evidence indicating that energy homeostasis and metabolism are modulated by adipose tissue and by pancreatic beta cells, the exclusive source of insulin $[44,45]$. Therefore, we assessed the effects of NPB on white adipocytes. First, we found that NPB and its receptor (NPBWR1) mRNA are expressed in isolated rat white preadipocytes and mature adipocytes. Moreover, our study demonstrated that by acting on isolated rat white adipocytes, NPB suppresses leptin mRNA expression and leptin secretion [27]. We also found that NPB stimulates lipolysis and resistin secretion [27]. Overall, these results suggest that NPB may protect against body weight gain by promoting lipolysis. Furthermore, keeping in mind that fat tissue is the main source of leptin, it cannot be excluded that the orexigenic effects of NPB reported by others may result from attenuated leptin production and secretion. In this context, it is worth noting that NPBWR1 - / - male mice have elevated levels of leptin in the blood [30]. Nevertheless, it was found that NPB administration in rats had no effect on circulating leptin levels [46]. Thus, the ability of NPB to regulate leptin expression and secretion in vivo is unclear and requires further experimentation.

In addition to the function of modulating white adipocytes, our recent data indicate that NPB may be involved in brown adipogenesis [28]. We demonstrated that NPB promotes proliferation of rat primary preadipocytes. We also found that NPB acting on rat brown preadipocytes stimulates the expression of adipogenic genes such as PRDM16 and UCP1, which indicates that NPB stimulates the differentiation of brown preadipocytes into mature adipocytes. It is worth noting that the stimulation of UCP1 expression is mediated by $\mathrm{p} 38$ kinase activation, the main protein kinase involved in brown adipogenesis [47]. Nevertheless, since our experiments were restricted to in vitro settings only, a question is raised about the physiological consequences of these findings. Importantly, the loss of brown adipose tissue is a hallmark of obesity, while the activation of brown fat in obese individuals leads to body weight loss $[48,49]$. Therefore, it cannot be excluded that the induction of body weight gain reported in NPB- or NPBWR1-deficient animals resulted from impaired brown adipogenesis. However, the role of the NPB/NPBWR1 system in controlling brown fat tissue formation remains unknown.

Finally, our recent in vitro study suggested that NPB may modulate glucose hemostasis by controlling insulin secretion. Using insulin-producing rat INS-1E cells and isolated 
rat pancreatic islets, we found that NPB stimulated insulin mRNA expression and secretion [17]. These results suggest that NPB and its receptors may contribute to glucose control through stimulation of insulin neogenesis and exocytosis. However, it should be pointed out that Rucinski et al. reported a lack of effects of NPB administration on circulating insulin levels in rats [46]. Therefore, the effects of NPB on insulin exocytosis in vivo are not yet fully understood.

In summary, by acting on mature white adipocytes, NPB promotes lipolysis while suppressing leptin expression and secretion. Furthermore, NPB promotes brown adipogenesis and insulin expression, and secretion in vitro. The effects of NPB on insulin expression and secretion in vivo are yet to be discovered.

\subsection{Adrenal Glands}

The adrenal glands play a pivotal role in the endocrine system. They mainly produce stress hormones and thus are involved in maintaining energy homeostasis and adaption of the organism to environmental changes [50]. Several research groups have investigated the role of the NPB/NPBWR1 system in the adrenal glands. First, it was found that NPB and NPBWR1 mRNA were expressed in freshly dispersed and 4-day cultured rat zona fasciculata/reticularis (ZF/R) cells [26]. The expression of NPB and NPBWR1 mRNA in rat zona glomerulosa (ZG) and ZF/R cells was confirmed by an independent study, which additionally showed that both genes were expressed in the adrenal medulla (AM) [51]. The expression of NPB and NPBWR1 and NPBWR2 mRNA was detected in ZG and ZF/R cells of adrenal cortexes [4]. The same study showed that NPB failed to modulate basal aldosterone secretion from zona granulosa cells [26]. In contrast, NPB potentiated ACTHstimulated aldosterone secretion. However, NPB was unable to affect cortisol release from ZF/R cells. Furthermore, it was reported that NPB is able to promote ZF/R cell proliferation [26]. The contribution of NPB to the modulation of adrenal gland functions was confirmed by an in vivo study. Samson et al. reported that i.c.v. administration of NPB (1 or 3 nmol) stimulated plasma corticosterone levels in male Sprague Dawley rats. Importantly, NPB-stimulated corticosterone levels were attenuated in rats pretreated with antiserum against corticotropin-releasing factor [32]. In addition, Mogi et al. found that the central administration of NPB increased circulating cortisol concentrations in sheep [52].

The effects of NPB on adrenal functions were also studied in human tissues. It was found that, consistent with the results of rat studies, NPB was not able to modulate aldosterone secretion from ZG cells [16]. On the other hand, NPB promoted cortisol release from ZF/R cells. Furthermore, it was shown that stimulation of cortisol secretion by NPB depends on activation of adenylate cyclase/PKA and phospholipase C/PKC signaling [16]. Andreis et al. studied the effects of NPB on the proliferation of human carcinoma-derived NCI-H295 cells (a surrogate model of human adrenocortical cells) [53]. The authors of this study demonstrated that both NPB receptors were expressed at the mRNA level [53]. The same study showed that NPB is able to promote NCI-H295 cell proliferation and suppress apoptosis [53]. The mitogenic action of NPB in NCI-H295 cells was mediated by tyrosine kinase-dependent ERK1/2 activation [53]. Of note, NPB failed to affect the secretion of cortisol or aldosterone from these cells. Hochol et al. studied the effects of NPB on adrenal gland functions using adrenal medulla-containing adrenal quarters [51]. Interestingly, in contrast to previously published data, this study showed that NPB downregulated ACTH-stimulated aldosterone secretion as well as basal and ACTH-stimulated cortisol secretion from adrenal quarters containing cortical and medullary tissues [51]. The same study showed that acute s.c. administration of NPB did not modulate circulating levels of ACTH or aldosterone but increased corticosterone. The role of NPB in controlling the HPA axis was additionally studied in sheep. It was found that i.c.v. injection of NPB $(0.5 \mathrm{nmol})$ increased the cortisol concentration in the blood [52]. In summary, these results collectively show that NPB and its receptors are expressed in the cortex and medulla of adrenal glands. NPB is also implicated in controlling cortisol and corticosterone secretion. 


\section{The Role of NPB and Its Receptors in Reproduction}

Few studies have addressed the role of NPB and its receptors in the regulation of reproductive functions. In the rat CNS, the expression of NPB mRNA was detected in the hypothalamus $[10,22]$, which is known as the crucial center of the reproductive hypothalamus-pituitary-gonadal regulatory axis [54]. More detailed analysis showed that, in the hypothalamus, NPB-immunoreactive cells are present in the paraventricular nucleus $(\mathrm{PVN})$, ventromedial hypothalamic nucleus $(\mathrm{VMH})$, dorsomedial hypothalamic nucleus $(\mathrm{DMH})$, and arcuate nucleus (ARC) [55]. Many regions within the hypothalamus also have high levels of NPBWR1 mRNA expression [55]. Of note, VMH activity is involved in sexual behavior, while ARC is importantly involved in GnRH and prolactin release from the anterior pituitary, LH surge, lactation, and growth hormone release [56].

Although NPB-expressing neurons were identified in rats [10,22], there is no information regarding sex differences with respect to the occurrence of NPB neurons in other mammals. However, importantly, Ishi et al. demonstrated that NPBWR1-deficient male mice exhibited a sex-specific phenotype of adult-onset obesity [30]. Additional studies showing the importance of NPB in reproduction and the expression of NBP in the CNS of medaka teleost fish (Oryzias latipes) were published by Kikuchi et al. [20] and HirakiKajiyma et al. [19]. Both studies confirmed that NPB is preferentially expressed in the female medaka brain, in populations of $\mathrm{Vs} / \mathrm{Vp}$ and $\mathrm{PMm} / \mathrm{PMg}$ neurons, whose expression is known to be estrogen-dependent and associated with female sexual receptivity [18]. NPB neurons in PMm/PMg regions are critically dependent on estrogen [20]. Behavioral studies indicated that NPB is a direct mediator of estrogen action in female mating behavior, acting in a female-specific and reversible manner [19]. Moreover, Hiraki-Kajiyma et al., using NPB-deficient medaka, showed that NPB/NPBWR2 signaling is involved in female sexual receptivity. The female-specific neurons located in PMm/PMg neurons are found in the region that is considered homologous to $\mathrm{SON} / \mathrm{PVN}$ in the mammalian brain. It is possible that the role of NPB in female sexual receptivity may be conserved across vertebrates; however, this hypothesis needs to be investigated.

Interesting data were obtained in non-mammalian vertebrates, using the chicken as a model, to examine the functionality of the NPB and NPW system and its interaction with the pituitary gland [21]. It was found that NPB mRNA is widely expressed in chicken tissues, including the hypothalamus, while chicken NPB receptor isoforms cNPBWR1 and CNPBWR2 were predominantly expressed in the brain and pituitary. One study confirmed NPB immunoreactivity detected in a population of cells in the rat anterior pituitary [57]. In another study, the mRNA expression of NPB and its two receptors was detected in the rat anterior pituitary gland [24]. Intermediate levels of NPBWR1 and NPBWR2 expression in the rat pituitary gland were also detected [12]. In vivo, i.c.v. injection of NPB into the lateral cerebral ventricle of male rats increased prolactin but decreased GH in the circulation [32].

mRNA expression of NPB was detected in peripheral reproductive glands including the ovary, uterus, placenta, testes, and mammary gland in rats [10,12]. Immunohistochemical detection of NPB in reproductive peripheral glands including ovarian thecal cells, granulosa and lutein cells, and oocytes and in Leydig cells of the testes was also reported [24]. For the first time, the functional role of NPB in the regulation of gonadal hormone secretion was analyzed in pigs [23]. Yang et al. confirmed NPB mRNA expression in porcine tissues such as the ovary and the testes, and NPBWR1 and NPBWR2 expression was detected in Leydig cells and ovarian granulosa cells. In vitro experiments showed that NPB promoted testosterone secretion in cultured Leydig cells in a dose-dependent manner. Different doses of NPB also upregulated progesterone secretion in primary cultures of ovarian pig granulosa cells. Low concentrations of NPB $\left(10^{-8}\right.$ and $\left.10^{-10} \mathrm{M}\right)$ increased estradiol secretion, but a higher dose $\left(10^{-6} \mathrm{M}\right)$ inhibited estradiol secretion, in granulosa cell cultures. The identification of the direct effects of NPB on steroid hormone secretion in pig ovarian and testicular cells suggests that the NPB/NPBWR1 or NPBWR2 system plays a role in modulating reproductive functions. NPB, similar to NPW, may play a role in regulating the rat endocrine system via ACTH/steroids. Hochol et al. showed that i.p. bolus 
injection of NPB or NPW increased plasma levels of parathyroid hormone, corticosterone, and testosterone. NPB also increased the blood concentration of thyroxine [24].

In summary, there are data suggesting that NPB and its receptors are involved in reproductive and sexual behavior functions. Nowadays, data collected from different and distant species of vertebrates indicate that neuropeptide $B$ is an important regulator of the hypothalamic-pituitary-gonadal axis.

\section{Other Effects of NPB}

NPB may contribute to the physiology of bones. Ziolkowska et al. reported that NPB and NPBWR1 were expressed in cultured rat calvarial osteoblast-like (ROB) cells [58]. The same study showed that NPB suppressed the proliferation of these cells while it had no effect on osteocalcin secretion [58]. These results indicate that NPB may contribute to the modulation of bone cell activity. In addition, discussing the role of NPB in peripheral tissues, it needs to be pointed out that a recent rat study demonstrated that NPB and its receptors are present in the heart [25]. NPB mRNA expression was detected in both atria and, at lower levels, both ventricles. Importantly, NPB was detected in the bodies of intracardiac ganglion neurons, suggesting that it may be considered as a neurotransmitter. The presence of NPB was also detected in nerve fibers, nerve cell bodies, and smooth muscle in the heart and ganglia. However, the authors of this study failed to detect NPB in cardiomyocyte cells. Due to limited data regarding the role of NPB in the cardiovascular system, it is difficult to speculate about its role in the heart. Nevertheless, based on the presence of NPB in smooth muscle cells of the coronary circulation, it was postulated that it may be involved in modulating the regulation of the coronary circulation [25]. Moreover, NPB expression was also detected in the intestine $[10,18,21,23]$, suggesting its potential role in controlling the gut-brain axis. Nevertheless, more experiments are needed to answer this point. In summary, NPB and its receptors may be involved in controlling bone cell and cardiovascular system functions. As shown in Table 1, NPB is widely expressed in numerous peripheral tissues. The biological effects of neuropeptide B are shown in Figure 1.

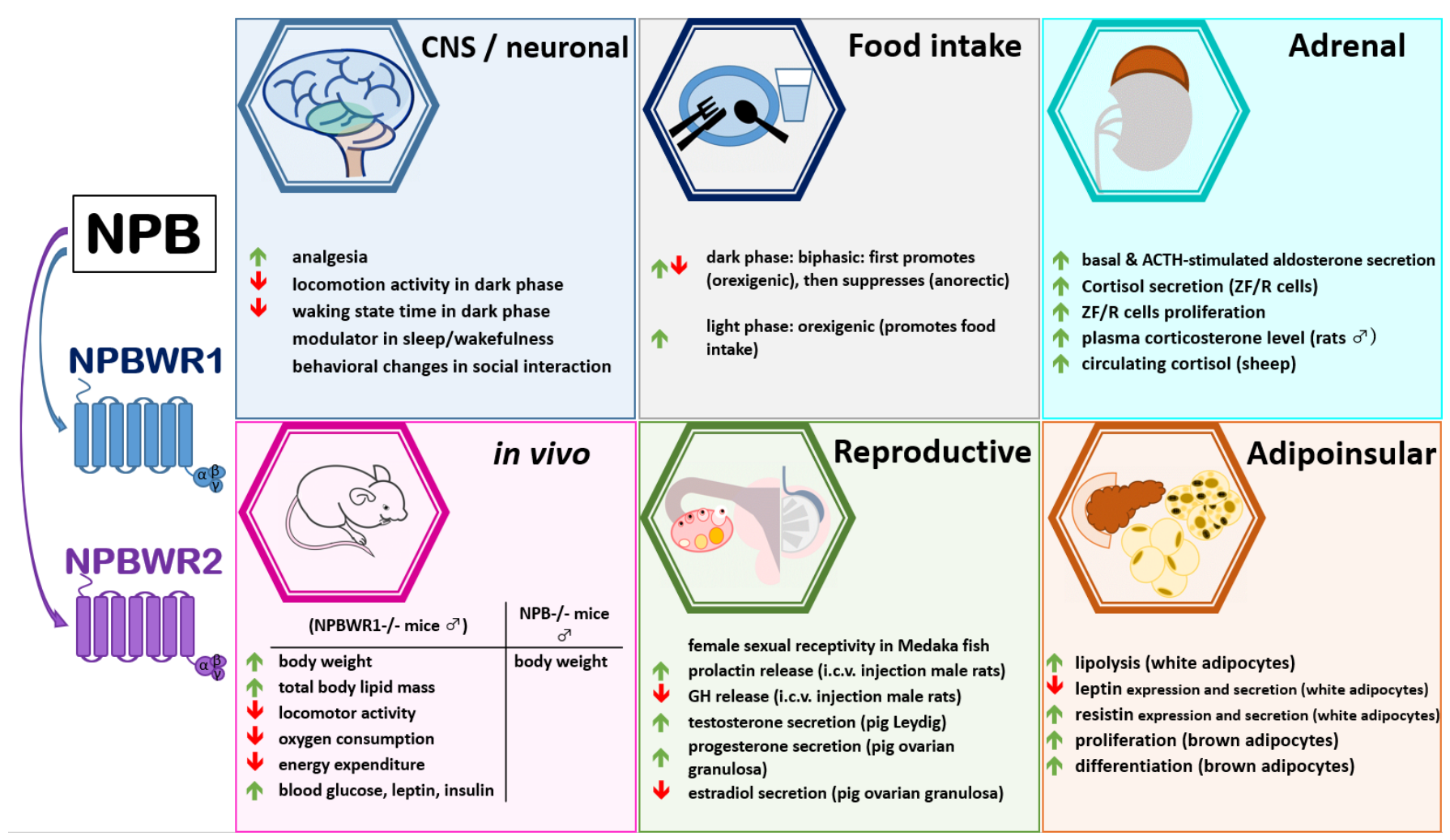

Figure 1. Biological effects of neuropeptide B. 


\section{Concluding Remarks}

Almost two decades after the discovery of NPB, there is growing evidence indicating its impact on appetite, reproduction, and a variety of endocrine activities in peripheral endocrine glands. Furthermore, studies of genetically engineered animals have shown us that NPB or NPBWR1 depletion is accompanied by increased body weight. In addition, recent data show that NPB may be positively involved in controlling insulin synthesis and secretion as well as promoting brown adipogenesis, which are important targets for therapy in diabetes and obesity. There is also evidence that NPB may be involved in controlling cardiovascular system and adrenal gland functions. These results suggest that NPB and its receptors should be considered in the development of therapy for human diseases such as obesity and type 2 diabetes.

Author Contributions: Conceptualization, T.W. and M.S.; writing—original draft preparation, T.W., M.B., M.J. and M.S.; writing-review and editing, K.W.N. and M.Z.S.; funding acquisition, T.W.; visualization, T.W.; supervision, T.W. and M.S. All authors have read and agreed to the published version of the manuscript.

Funding: This work was supported by the National Science Centre of Poland (grant number 2016/21/B/NZ9/00943 to T. Wojciechowicz) and co-financed by statutory funding of the Faculty of Veterinary Medicine and Animal Science Poznan University of Life Sciences (506.558.09.00, 506.558.04.00 and 506.558.05.00), financed by the Polish Ministry of Science and Higher Education.

Conflicts of Interest: The authors declare no conflict of interest.

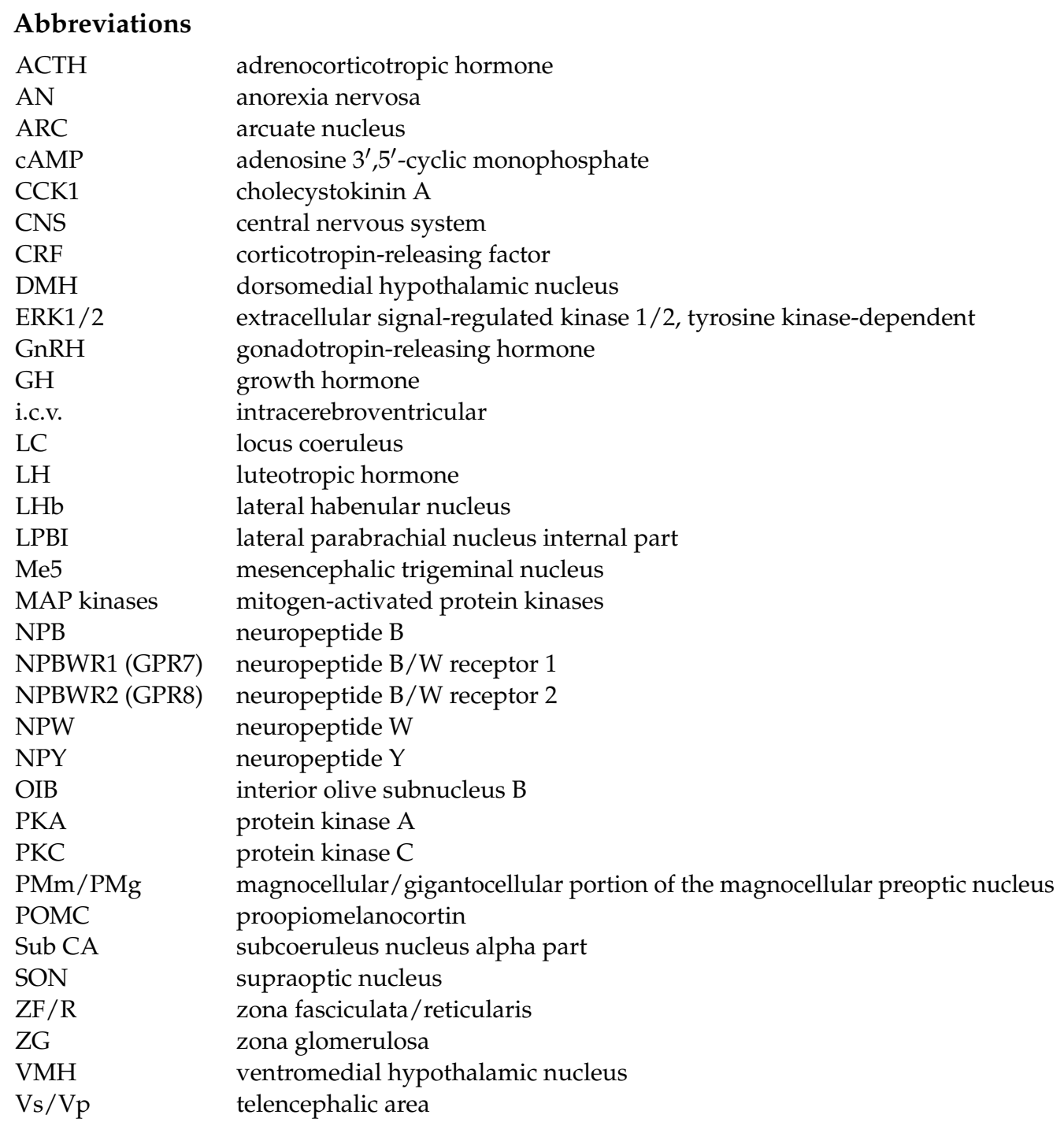




\section{References}

1. Greenwood, H.C.; Bloom, S.R.; Murphy, K.G. Peptides and their potential role in the treatment of diabetes and obesity. Rev. Diabet. Stud. RDS 2011, 8, 355-368. [CrossRef]

2. Timper, K.; Bruning, J.C. Hypothalamic circuits regulating appetite and energy homeostasis: Pathways to obesity. Dis. Models Mech. 2017, 10, 679-689. [CrossRef] [PubMed]

3. Murphy, K.G.; Bloom, S.R. Gut hormones and the regulation of energy homeostasis. Nature 2006, 444, 854-859. [CrossRef]

4. Kołodziejski, P.A.; Pruszyńska-Oszmałek, E.; Wojciechowicz, T.; Sassek, M.; Leciejewska, N.; Jasaszwili, M.; Billert, M.; Małek, E.; Szczepankiewicz, D.; Misiewicz-Mielnik, M. The Role of Peptide Hormones Discovered in the 21st Century in the Regulation of Adipose Tissue Functions. Genes 2021, 12, 756. [CrossRef]

5. Dudek, M.; Ziarniak, K.; Sliwowska, J.H. Kisspeptin and Metabolism: The Brain and Beyond. Front. Endocrinol. 2018, 9, 145. [CrossRef]

6. Skrzypski, M.; Billert, M.; Nowak, K.W.; Strowski, M.Z. The role of orexin in controlling the activity of the adipo-pancreatic axis. J. Endocrinol. 2018, 238, R95-R108. [CrossRef] [PubMed]

7. Macedonio, G.; Stefanucci, A.; Maccallini, C.; Mirzaie, S.; Novellino, E.; Mollica, A. Hemopressin Peptides as Modulators of the Endocannabinoid System and their Potential Applications as Therapeutic Tools. Protein Pept. Lett. 2016, 23, 1045-1051. [CrossRef]

8. Stefanucci, A.; Macedonio, G.; Dvoracsko, S.; Tomboly, C.; Mollica, A. Novel Fubinaca/Rimonabant hybrids as endocannabinoid system modulators. Amino Acids 2018, 50, 1595-1605. [CrossRef]

9. Dimmito, M.P.; Stefanucci, A.; Pieretti, S.; Minosi, P.; Dvoracsko, S.; Tomboly, C.; Zengin, G.; Mollica, A. Discovery of Orexant and Anorexant Agents with Indazole Scaffold Endowed with Peripheral Antiedema Activity. Biomolecules 2019, 9, 492. [CrossRef]

10. Fujii, R.; Yoshida, H.; Fukusumi, S.; Habata, Y.; Hosoya, M.; Kawamata, Y.; Yano, T.; Hinuma, S.; Kitada, C.; Asami, T.; et al. Identification of a neuropeptide modified with bromine as an endogenous ligand for GPR7. J. Biol. Chem. 2002, 277, 34010-34016. [CrossRef]

11. Tanaka, H.; Yoshida, T.; Miyamoto, N.; Motoike, T.; Kurosu, H.; Shibata, K.; Yamanaka, A.; Williams, S.C.; Richardson, J.A.; Tsujino, N.; et al. Characterization of a family of endogenous neuropeptide ligands for the G protein-coupled receptors GPR7 and GPR8. Proc. Natl. Acad. Sci. USA 2003, 100, 6251-6256. [CrossRef]

12. Brezillon, S.; Lannoy, V.; Franssen, J.D.; Le Poul, E.; Dupriez, V.; Lucchetti, J.; Detheux, M.; Parmentier, M. Identification of natural ligands for the orphan G protein-coupled receptors GPR7 and GPR8. J. Biol. Chem. 2003, 278, 776-783. [CrossRef] [PubMed]

13. O'Dowd, B.F.; Scheideler, M.A.; Nguyen, T.; Cheng, R.; Rasmussen, J.S.; Marchese, A.; Zastawny, R.; Heng, H.H.; Tsui, L.C.; Shi, X.; et al. The cloning and chromosomal mapping of two novel human opioid-somatostatin-like receptor genes, GPR7 and GPR8, expressed in discrete areas of the brain. Genomics 1995, 28, 84-91. [CrossRef]

14. Lee, D.K.; Nguyen, T.; Porter, C.A.; Cheng, R.; George, S.R.; O’Dowd, B.F. Two related G protein-coupled receptors: The distribution of GPR7 in rat brain and the absence of GPR8 in rodents. Brain Res. Mol. Brain Res. 1999, 71, 96-103. [CrossRef]

15. Shimomura, Y.; Harada, M.; Goto, M.; Sugo, T.; Matsumoto, Y.; Abe, M.; Watanabe, T.; Asami, T.; Kitada, C.; Mori, M.; et al. Identification of neuropeptide $\mathrm{W}$ as the endogenous ligand for orphan G-protein-coupled receptors GPR7 and GPR8. J. Biol. Chem. 2002, 277, 35826-35832. [CrossRef] [PubMed]

16. Mazzocchi, G.; Rebuffat, P.; Ziolkowska, A.; Rossi, G.P.; Malendowicz, L.K.; Nussdorfer, G.G. G protein receptors 7 and 8 are expressed in human adrenocortical cells, and their endogenous ligands neuropeptides $\mathrm{B}$ and w enhance cortisol secretion by activating adenylate cyclase- and phospholipase C-dependent signaling cascades. J. Clin. Endocrinol. Metab. 2005, 90, 3466-3471. [CrossRef]

17. Billert, M.; Sassek, M.; Wojciechowicz, T.; Jasaszwili, M.; Strowski, M.Z.; Nowak, K.W.; Skrzypski, M. Neuropeptide B stimulates insulin secretion and expression but not proliferation in rat insulinproducing INS1E cells. Mol. Med. Rep. 2019, 20, $2030-2038$. [CrossRef]

18. Hiraki, T.; Nakasone, K.; Hosono, K.; Kawabata, Y.; Nagahama, Y.; Okubo, K. Neuropeptide B is female-specifically expressed in the telencephalic and preoptic nuclei of the medaka brain. Endocrinology 2014, 155, 1021-1032. [CrossRef]

19. Hiraki-Kajiyama, T.; Yamashita, J.; Yokoyama, K.; Kikuchi, Y.; Nakajo, M.; Miyazoe, D.; Nishiike, Y.; Ishikawa, K.; Hosono, K.; Kawabata-Sakata, Y.; et al. Neuropeptide B mediates female sexual receptivity in medaka fish, acting in a female-specific but reversible manner. eLife 2019, 8. [CrossRef]

20. Kikuchi, Y.; Hiraki-Kajiyama, T.; Nakajo, M.; Umatani, C.; Kanda, S.; Oka, Y.; Matsumoto, K.; Ozawa, H.; Okubo, K. Sexually Dimorphic Neuropeptide B Neurons in Medaka Exhibit Activated Cellular Phenotypes Dependent on Estrogen. Endocrinology 2019, 160, 827-839. [CrossRef]

21. Bu, G.; Lin, D.; Cui, L.; Huang, L.; Lv, C.; Huang, S.; Wan, Y.; Fang, C.; Li, J.; Wang, Y. Characterization of Neuropeptide B (NPB), Neuropeptide W (NPW), and Their Receptors in Chickens: Evidence for NPW Being a Novel Inhibitor of Pituitary GH and Prolactin Secretion. Endocrinology 2016, 157, 3562-3576. [CrossRef]

22. Jackson, V.R.; Lin, S.H.; Wang, Z.; Nothacker, H.P.; Civelli, O. A study of the rat neuropeptide B/neuropeptide W system using in situ techniques. J. Comp. Neurol. 2006, 497, 367-383. [CrossRef] [PubMed]

23. Yang, S.; Ma, Z.; Suo, C.; Cheng, L.; Su, J.; Lei, Z. Cloning and mRNA expression of NPB and its effect on hormone secretion of the reproductive cells in the pig. Gen. Comp. Endocrinol. 2018, 261, 97-103. [CrossRef] 
24. Hochol, A.; Belloni, A.S.; Rucinski, M.; Ziolkowska, A.; Di Liddo, R.; Nussdorfer, G.G.; Malendowicz, L.K. Expression of neuropeptides $\mathrm{B}$ and $\mathrm{W}$ and their receptors in endocrine glands of the rat. Int. J. Mol. Med. 2006, 18, 1101-1106. [CrossRef] [PubMed]

25. Pandey, S.; Tuma, Z.; Peroni, E.; Monasson, O.; Papini, A.M.; Chottova Dvorakova, M. Identification of NPB, NPW and Their Receptor in the Rat Heart. Int. J. Mol. Sci. 2020, 21, 7827. [CrossRef] [PubMed]

26. Hochol, A.; Albertin, G.; Nussdorfer, G.G.; Spinazzi, R.; Ziolkowska, A.; Rucinski, M.; Malendowicz, L.K. Effects of neuropeptides $\mathrm{B}$ and $\mathrm{W}$ on the secretion and growth of rat adrenocortical cells. Int. J. Mol. Med. 2004, 14, 843-847. [CrossRef]

27. Skrzypski, M.; Pruszynska-Oszmalek, E.; Rucinski, M.; Szczepankiewicz, D.; Sassek, M.; Wojciechowicz, T.; Kaczmarek, P.; Kolodziejski, P.A.; Strowski, M.Z.; Malendowicz, L.K.; et al. Neuropeptide B and W regulate leptin and resistin secretion, and stimulate lipolysis in isolated rat adipocytes. Regul. Pept. 2012, 176, 51-56. [CrossRef]

28. Wojciechowicz, T.; Billert, M.; Dhandapani, P.; Szczepankiewicz, D.; Wasielewski, O.; Strowski, M.Z.; Nowak, K.W.; Skrzypski, M. Neuropeptide B promotes proliferation and differentiation of rat brown primary preadipocytes. FEBS Open Bio 2021. [CrossRef]

29. Nakayama, N.; Suzuki, H.; Li, J.B.; Atsuchi, K.; Tsai, M.; Amitani, H.; Asakawa, A.; Inui, A. The role of CRF family peptides in the regulation of food intake and anxiety-like behavior. Biomol. Concepts 2011, 2, 275-280. [CrossRef]

30. Ishii, M.; Fei, H.; Friedman, J.M. Targeted disruption of GPR7, the endogenous receptor for neuropeptides B and W, leads to metabolic defects and adult-onset obesity. Proc. Natl. Acad. Sci. USA 2003, 100, 10540-10545. [CrossRef]

31. Sohn, J.W. Network of hypothalamic neurons that control appetite. BMB Rep. 2015, 48, 229-233. [CrossRef] [PubMed]

32. Samson, W.K.; Baker, J.R.; Samson, C.K.; Samson, H.W.; Taylor, M.M. Central neuropeptide B administration activates stress hormone secretion and stimulates feeding in male rats. J. Neuroendocrinol. 2004, 16, 842-849. [CrossRef]

33. Kelly, M.A.; Beuckmann, C.T.; Williams, S.C.; Sinton, C.M.; Motoike, T.; Richardson, J.A.; Hammer, R.E.; Garry, M.G.; Yanagisawa, M. Neuropeptide B-deficient mice demonstrate hyperalgesia in response to inflammatory pain. Proc. Natl. Acad. Sci. USA 2005, 102, 9942-9947. [CrossRef]

34. Yang, L.; Sun, C.; Li, W. Neuropeptide B in Nile tilapia Oreochromis niloticus: Molecular cloning and its effects on the regulation of food intake and mRNA expression of growth hormone and prolactin. Gen. Comp. Endocrinol. 2014, 200, 27-34. [CrossRef]

35. Perry, B.; Wang, Y. Appetite regulation and weight control: The role of gut hormones. Nutr. Diabetes 2012, 2, e26. [CrossRef]

36. Grzelak, T.; Tyszkiewicz-Nwafor, M.; Dutkiewicz, A.; Mikulska, A.A.; Dmitrzak-Weglarz, M.; Slopien, A.; Czyzewska, K.; Paszynska, E. Neuropeptide B and Vaspin as New Biomarkers in Anorexia Nervosa. BioMed Res. Int. 2018, 2018, 9727509. [CrossRef]

37. Grzelak, T.; Tyszkiewicz-Nwafor, M.; Dutkiewicz, A.; Mikulska, A.A.; Dmitrzak-Weglarz, M.; Slopien, A.; Czyzewska, K.; Paszynska, E. Vaspin (but not neuropeptide B or neuropeptide W) as a possible predictor of body weight normalization in anorexia nervosa. Arch. Med. Sci. AMS 2021, 17, 376-381. [CrossRef]

38. Hirashima, N.; Tsunematsu, T.; Ichiki, K.; Tanaka, H.; Kilduff, T.S.; Yamanaka, A. Neuropeptide B induces slow wave sleep in mice. Sleep 2011, 34, 31-37. [CrossRef] [PubMed]

39. Lau, B.K.; Winters, B.L.; Vaughan, C.W. Opioid presynaptic disinhibition of the midbrain periaqueductal grey descending analgesic pathway. Br. J. Pharmacol. 2020, 177, 2320-2332. [CrossRef]

40. Yamamoto, T.; Saito, O.; Shono, K.; Tanabe, S. Anti-hyperalgesic effects of intrathecally administered neuropeptide W-23, and neuropeptide B, in tests of inflammatory pain in rats. Brain Res. 2005, 1045, 97-106. [CrossRef] [PubMed]

41. Cimpean, A.; David, D. The mechanisms of pain tolerance and pain-related anxiety in acute pain. Health Psychol. Open 2019, 6, 2055102919865161. [CrossRef] [PubMed]

42. Nagata-Kuroiwa, R.; Furutani, N.; Hara, J.; Hondo, M.; Ishii, M.; Abe, T.; Mieda, M.; Tsujino, N.; Motoike, T.; Yanagawa, Y.; et al. Critical role of neuropeptides B/W receptor 1 signaling in social behavior and fear memory. PLoS ONE 2011, 6, e16972. [CrossRef]

43. Watanabe, N.; Wada, M.; Irukayama-Tomobe, Y.; Ogata, Y.; Tsujino, N.; Suzuki, M.; Furutani, N.; Sakurai, T.; Yamamoto, M. A single nucleotide polymorphism of the neuropeptide $\mathrm{B} / \mathrm{W}$ receptor-1 gene influences the evaluation of facial expressions. PLoS ONE 2012, 7, e35390. [CrossRef]

44. Trayhurn, P.; Beattie, J.H. Physiological role of adipose tissue: White adipose tissue as an endocrine and secretory organ. Proc. Nutr. Soc. 2001, 60, 329-339. [CrossRef] [PubMed]

45. Wilcox, G. Insulin and insulin resistance. Clin. Biochem. Rev. 2005, 26, 19-39.

46. Rucinski, M.; Nowak, K.W.; Chmielewska, J.; Ziolkowska, A.; Malendowicz, L.K. Neuropeptide W exerts a potent suppressive effect on blood leptin and insulin concentrations in the rat. Int. J. Mol. Med. 2007, 19, 401-405. [CrossRef]

47. Cao, W.; Daniel, K.W.; Robidoux, J.; Puigserver, P.; Medvedev, A.V.; Bai, X.; Floering, L.M.; Spiegelman, B.M.; Collins, S. p38 mitogen-activated protein kinase is the central regulator of cyclic AMP-dependent transcription of the brown fat uncoupling protein 1 gene. Mol. Cell. Biol. 2004, 24, 3057-3067. [CrossRef]

48. Cypess, A.M.; Kahn, C.R. Brown fat as a therapy for obesity and diabetes. Curr. Opin. Endocrinol. Diabetes Obes. 2010, 17, 143-149. [CrossRef]

49. Alcala, M.; Calderon-Dominguez, M.; Serra, D.; Herrero, L.; Viana, M. Mechanisms of Impaired Brown Adipose Tissue Recruitment in Obesity. Front. Physiol. 2019, 10, 94. [CrossRef]

50. Kargi, A.Y.; Iacobellis, G. Adipose tissue and adrenal glands: Novel pathophysiological mechanisms and clinical applications. Int. J. Endocrinol. 2014, 2014, 614074. [CrossRef] [PubMed] 
51. Hochol, A.; Tortorella, C.; Ricinski, M.; Ziolkowska, A.; Nussdorfer, G.G.; Malendowicz, L.K. Effects of neuropeptides B and W on the rat pituitary-adrenocortical axis: In vivo and in vitro studies. Int. J. Mol. Med. 2007, 19, 207-211. [CrossRef]

52. Mogi, K.; Ito, S.; Matsuyama, S.; Ohara, H.; Sakumoto, R.; Yayou, K.; Ohkura, S.; Sutoh, M.; Mori, Y.; Okamura, H. Central administration of neuropeptide B, but not prolactin-releasing peptide, stimulates cortisol secretion in sheep. J. Reprod. Dev. 2008, 54, 138-141. [CrossRef]

53. Andreis, P.G.; Rucinski, M.; Neri, G.; Conconi, M.T.; Petrelli, L.; Parnigotto, P.P.; Malendowicz, L.K.; Nussdorfer, G.G. Neuropeptides $\mathrm{B}$ and $\mathrm{W}$ enhance the growth of human adrenocortical carcinoma-derived NCI-H295 cells by exerting MAPK p42/p44-mediated proliferogenic and antiapoptotic effects. Int. J. Mol. Med. 2005, 16, 1021-1028. [CrossRef]

54. McClellan, K.M.; Parker, K.L.; Tobet, S. Development of the ventromedial nucleus of the hypothalamus. Front. Neuroendocrinol. 2006, 27, 193-209. [CrossRef]

55. Schulz, S.; Stumm, R.; Hollt, V. Immunofluorescent identification of neuropeptide B-containing nerve fibers and terminals in the rat hypothalamus. Neurosci. Lett. 2007, 411, 67-71. [CrossRef] [PubMed]

56. Sakurai, T. NPBWR1 and NPBWR2: Implications in Energy Homeostasis, Pain, and Emotion. Front. Endocrinol. $2013,4,23$. [CrossRef] [PubMed]

57. Dun, S.L.; Brailoiu, G.C.; Mizuo, K.; Yang, J.; Chang, J.K.; Dun, N.J. Neuropeptide B immunoreactivity in the central nervous system of the rat. Brain Res. 2005, 1045, 157-163. [CrossRef] [PubMed]

58. Ziolkowska, A.; Rucinski, M.; Tyczewska, M.; Malendowicz, L.K. Neuropeptide B (NPB) and neuropeptide W (NPW) system in cultured rat calvarial osteoblast-like (ROB) cells: NPW and NPB inhibit proliferative activity of ROB cells. Int. J. Mol. Med. 2009, 24, 781-787. [CrossRef] [PubMed] 